\title{
BMJ Open Patients with heart failure with and without a history of stroke in the Netherlands: a secondary analysis of psychosocial, behavioural and clinical outcomes up to three years from the $\mathrm{COACH}$ trial
}

Chantal F Ski, ${ }^{1}$ Martje H L van der Wal, ${ }^{2,3}$ Michael Le Grande, ${ }^{4}$ Dirk J. van Veldhuisen, ${ }^{2}$ Ivonne Lesman-Leegte, ${ }^{5}$ David R Thompson, ${ }^{1}$ Sandy Middleton, ${ }^{\oplus 6}$ Jan Cameron, ${ }^{7}$ Tiny Jaarsma ${ }^{3}$

To cite: Ski CF, van der Wal MHL, Le Grande M, et al. Patients with heart failure with and without a history of stroke in the Netherlands: a secondary analysis of psychosocial, behavioural and clinical outcomes up to three years from the $\mathrm{COACH}$ trial. BMJ Open 2019;9:e025525. doi:10.1136/ bmjopen-2018-025525

- Prepublication history for this paper is available online. To view these files please visit the journal online (http://dx.doi org/10.1136/bmjopen-2018025525).

Received 19 July 2018 Revised 3 June 2019 Accepted 7 June 2019

Check for updates

(C) Author(s) (or their employer(s)) 2019. Re-use permitted under CC BY-NC. No commercial re-use. See rights and permissions. Published by BMJ.

For numbered affiliations see end of article.

Correspondence to

Dr Tiny Jaarsma;

tiny.jaarsma@liu.se

\section{ABSTRACT}

Objective To identify differences in psychosocial, behavioural and clinical outcomes between patients with heart failure (HF) with and without stroke.

Design and participants A secondary analysis of 1023 patients with heart failure enrolled in the Coordinating study evaluating Outcomes of Advising and Counselling in Heart failure.

Setting Seventeen hospitals located across the Netherlands. Outcomes measures Depressive symptoms (Centre for Epidemiological Studies Depression Scale), quality of life (Minnesota Living with Heart Failure Questionnaire, Ladder of Life Scale), self-care (European Heart Failure Self-Care Behaviour Scale), adherence to HF management (modified version of the Heart Failure Compliance Questionnaire) and readmission for $\mathrm{HF}$, cardiovascular-cause and all-cause hospitalisations at 18 months, and all-cause mortality at 18 months and 3 years.

Results Compared with those without stroke, patients with HF with a stroke (10.3\%; $n=105)$ had twice the likelihood of severe depressive symptoms (OR $2.83,95 \% \mathrm{Cl} 1.27$ to 6.28 , $\mathrm{p}=0.011$; $\mathrm{OR} 2.24,95 \% \mathrm{Cl} 1.03$ to $4.88, \mathrm{p}=0.043$ ) at 12 and 18 months, poorer disease-specific and generic quality of life (OR 2.80, 95\% Cl 1.61 to $4.84, \mathrm{p}<0.001 ; \mathrm{OR} 2.00,95 \% \mathrm{Cl}$ 1.09 to $3.50, p=0.019)$ at 12 months, poorer self-care (OR $1.80,95 \% \mathrm{Cl} 1.05$ to $3.11, \mathrm{p}=0.034 ; \mathrm{OR} 2.87,95 \% \mathrm{Cl} 1.61$ to $5.11, \mathrm{p}<0.0011$ ) and $\mathrm{HF}$ management adherence (OR 0.39 , $95 \% \mathrm{Cl} 0.18$ to $0.81, \mathrm{p}=0.012$; $\mathrm{OR} 0.35,95 \% \mathrm{Cl} 0.17$ to 0.72 , $\mathrm{p}=0.004$ ) at 12 and 18 months, higher rates of hospitalisations and mortality at 18 months and higher all-cause mortality (HR $1.43,95 \% \mathrm{Cl} 1.07$ to $1.91, \mathrm{p}=0.016$ ) at 3 years.

Conclusions Patients with HF and stroke have worse psychosocial, behavioural and clinical outcomes, notably from 12 months, than those without stroke. To ameliorate these poor outcomes long-term, integrated disease management pathways are warranted.

\section{INTRODUCTION}

Heart failure (HF) is an increasing pandemic characterised by high morbidity, mortality

\section{Strengths and limitations of this study}

- A secondary analysis of data from one of the largest multicentre $(n=17)$ randomised controlled trials of heart failure disease management.

- Comprehensive psychosocial, behavioural and clinical outcome data.

- Absence of a measure of stroke severity may have impeded interpretation of clinical outcomes.

- Limited generalisability due to small proportion of patients with severe heart failure.

and poor quality of life. ${ }^{1}$ Stroke, the second leading global cause of death $(11.8 \%)$ is a frequent comorbidity in patients with $\mathrm{HF}^{2}$ Stroke and HF commonly coexist because of shared vascular risk factors, ${ }^{34}$ and $\mathrm{HF}$ is associated with a twofold to threefold increased risk of ischaemic stroke $\mathrm{e}^{5-8}$ and is an independent predictor of death and disability and hospital readmissions after stroke at 30 days. ${ }^{6}$ Around $15 \%$ of patients with HF seen in HF clinics on a regular basis have a history of stroke. ${ }^{9}$ Having both HF and stroke contributes to a worse prognosis. ${ }^{36}$

Research has focused on the aetiology and pathophysiology of this comorbidity ${ }^{3} 810$ rather than its psychosocial and behavioural characteristics. This is despite strong evidence linking factors such as depression and lack of social support to adverse outcomes in patients with stroke ${ }^{1112}$ and $\mathrm{HF}^{1314}$ and attesting to the efficacy of psychosocial and behavioural interventions on outcomes such as psychological adjustment, social support and lifestyle changes to reduce cardiovascular risk. ${ }^{15-17}$ Attaining ideal cardiovascular health metrics 
such as quitting smoking and adopting a healthy diet can prevent up to $80 \%$ of cardiovascular disease ${ }^{18}$ lower risk of total and cardiovascular disease mortality ${ }^{19}$ and lower rates of stroke, incident $\mathrm{HF}$ and lifetime risk of $\mathrm{HF}^{20}$

Associations between lifestyle factors and $\mathrm{HF}$ and stroke, and their persistent poor prognosis, are well established, but evidence is deficient in psychosocial and behavioural comparisons of HF populations with and without stroke across the illness trajectory. Thus, we aimed to identify differences in psychosocial (depression, well-being, quality of life), behavioural (self-care, treatment adherence) and clinical (rehospitalisations, mortality) outcomes at baseline, 6, 12 and 18 months and mortality at 3 years between patients with HF with and without a history of stroke.

\section{METHODS}

\section{Study patients and trial procedures}

Coordinating study evaluating Outcome of Advising and Counselling in Heart failure (COACH) was a multicentre (17 hospitals in the Netherlands), prospective randomised HF disease management trial designed to compare basic support and intensive support in patients with chronic HF using blinded end-point evaluation. Patients who were admitted for $\mathrm{HF}$ were enrolled in $\mathrm{COACH}$ before discharge, and randomised to care as usual or to one of two levels of care, basic or intensive, of nurse-led intervention. Inclusion criteria were an admission for HF, evidence of a structural underlying heart disease and age $\geq 18$ years. 'History of stroke' was confirmed by medical records. Only those patients with complete data were included. The design and primary results of $\mathrm{COACH}$ have been described. $^{21} 22$ All data collected were part of the original $\mathrm{COACH}$ trial. The $\mathrm{COACH}$ trial was performed in accordance with principles outlined in the Declaration of Helsinki and was approved by a central medical ethical committee, Medical Ethical Committee Groningen (MEtC) 2002/047, and also by the medical ethics committee in each participating centre. This secondary analysis of data was exempt from further ethics approval as no additional data was collected and no significant additional harm was posed to patients.

Patients were interviewed and medical records were examined to obtain relevant demographic, clinical, psychosocial and behavioural data at baseline (hospital discharge), 6, 12 and 18 months thereafter. Additionally, all-cause mortality data were collected at 3 years.

\section{Data collection}

\section{Demographic and clinical data}

Basic demographic (age, gender) and clinical data (comorbidities, cardiovascular risk factors, disease severity) were collected at baseline.

\section{Psychosocial endpoints}

Depressive symptoms were measured with the Centre for Epidemiological Studies Depression Scale (CES-D), ${ }^{23}$ a 20-item clinically validated self-report questionnaire that assesses depressive symptoms in the general population and the medically ill. Scores range from 0 to 60 ; higher scores indicate more severe depressive symptoms. Cut-off scores of $\geq 16$ indicating moderate depression and $\geq 24$ for severe depression have been used extensively. ${ }^{24}$

Disease specific quality of life was measured with the Minnesota Living with Heart Failure Questionnaire (MLHFQ) ${ }^{25}$ a 21 -item self-report questionnaire that assesses patients' perceptions of the effects of their HF on quality of life. Degree of impairment on physical, social, psychological and socioeconomic domains is rated on a 6-point Likert scale from 0 (none) to 5 (very much); higher scores indicate poorer quality of life. A cut-off score of $>45$ indicates poor quality of life. ${ }^{26}$

Generic quality of life was measured with the Ladder of Life Scale (LLS), ${ }^{27}$ a 1-item measure of global wellbeing. Individuals are asked to place themselves on an 11-step ladder with 'worst possible life' representing the lowest rung (score $=0$ ) and 'best possible life' the top rung (score $=10)$. The Ladder of Life has been used in various cardiovascular studies and is considered a valid measure of subjective well-being. ${ }^{28}$

\section{Behavioural endpoints}

Self-care was measured with the European Heart Failure Self-Care Behaviour Scale (EHFScBS-9), ${ }^{29}$ a 9-item self-report questionnaire. The nine items are answered on a 5 -point Likert scale ( $1=$ completely agree; $5=$ completely disagree) and are converted to a standardised score ranging from 0 to 100 with a higher score indicating better self-care. ${ }^{30}$ Inadequate self-care behaviour has been identified as a standardised score below 70. A clinically meaningful change is represented by a smallest real difference of 5.75 points in EHFScBS-9 scores. ${ }^{31}$ One internally consistent subscale can be identified in the EHFScBS, namely 'consulting behaviours'. Consulting behaviours investigate how often people with HF call their doctor/nurse in case of shortness of breath, ankle swelling, weight gain and fatigue. The EHFScBS-9 has been implemented and validated across numerous countries world-wide. ${ }^{32}$

Adherence to $\mathrm{HF}$ management was measured with a modified version of the Heart Failure Compliance Questionnaire $(\mathrm{HFCQ})^{33}$ that assesses adherence in: meeting appointments, taking medication, weighing, diet, fluid intake and exercise. Items were rated on a 5-point Likert scale $(0=$ never, $1=$ seldom, $2=$ half of the time, $3=$ mostly, $4=$ always). Content validity was established in a HF population (Cronbach's $\alpha=0.68) .{ }^{33}$ Patients were classified as 'adherent' if they selected 'mostly' or 'always' and were defined as 'overall adherent' if they adhered to at least four of the six behaviours. ${ }^{34}$

\section{Clinical endpoints}

Clinical endpoints comprised HF, cardiovascular and all-cause hospitalisations at 18 months, and all-cause mortality at 18 months and 3 years. An end-point 
committee comprising two cardiologists and a geriatrician adjudicated whether hospitalisations and death were related to HF, cardiovascular death or cardiovascular events. Data on all-cause mortality were collected from the hospital registry, general practitioner and/or municipality at 3 years for each patient.

\section{Statistical analyses}

A preliminary analysis using $\mathrm{X}^{2}$ statistic was conducted to identify differences in proportions of patients with $\mathrm{HF}$ with, and without, stroke across intervention and control groups (care as usual, basic support, intensive support groups). Descriptive values are presented as mean $( \pm \mathrm{SD})$ for continuous variables or as percentages for categorical variables. Continuous variables were compared between patients with and without a history of stroke at baseline, 6 , 12 and 18 months using independent t-test, unequal variances t-test or Mann-Whitney U test where appropriate. A Bonferroni correction was applied to adjust for multiple comparisons across all baseline variables $(\mathrm{p}<0.002)$.

Variables with a $\mathrm{p}$ value less than 0.05 in the analysis comparing patients with HF with and without a history of stroke at baseline were consecutively subjected to a multivariate logistic regression model to assess the independent impact of each risk factor on major or severe depressive status (CES-D $\geq 16$ and CES-D $\geq 24$ ). The variables age and gender were chosen a priori as covariates in each model. A variance inflation factor (VIF) was calculated to ensure that two or more explanatory variables included in a multiple logistic regression model were not highly correlated. If two patient characteristics showed high multicollinearity (VIF $>3$ ) the least significant variable was excluded from the model. The model was estimated using the stepwise backward method (Wald) with a $p$ value of less than 0.05 to enter and a $p$ value of 0.10 to eliminate variables. This approach was repeated in order to identify significant predictors of: quality of life (MLHFQ $^{25}$ and LLS), ${ }^{27}$ HF management adherence $(\text { HFCQ })^{33}$ and self-care behaviour (EHFScBS) ${ }^{29}$

Self-care subscale standardised scores of the EHFScBS were subjected to repeated measures analysis of covariance, with scores at baseline, 12 and 18 months as the dependent variable, HF with a history of stroke as the between-subjects factor, and significantly different variables with a p-value less than 0.05 at baseline, with the addition of age and gender (chosen a priori) as covariates.

Event rates for clinical endpoints for patients with HF with and without stroke were analysed for cardiovascular, $\mathrm{HF}$ and all-cause rehospitalisations at 18 months, and for all-cause mortality at 18 months and 3 years using Kaplan-Meier curves and compared with the log-rank test. HRs and $95 \%$ CI were calculated by means of the Cox proportional hazards regression model. The proportional hazard assumption was tested based on Schoenfeld residuals. Variables showing a $\mathrm{p}$ value $<0.1$ derived from the univariate analysis, as well as sex and New York Heart Association (NYHA) functional status, were included in multivariable Cox models. A more conservative $\mathrm{p}$ value was used to avoid overfitting the model. Data were analysed using SPSS V.22.

\section{Patient and public involvement}

This project involved secondary data analysis and thus did not involve patients. The study design and primary analysis are described elsewhere. ${ }^{21} 22$

\section{RESULTS}

\section{Preliminary analyses}

No differences in proportions of patients with HF with and without stroke across intervention and control groups were identified using Chi-square statistic.

\section{Differences in HF patient characteristics with and without stroke}

Of the 1023 patients enrolled in COACH, 105 (10.3\%) had a documented history of stroke. Table 1 shows the baseline demographic and clinical characteristics. No significant differences were found for psychosocial or behavioural variables between patients with HF with and without stroke. Significant differences were found for the comorbidities type 2 diabetes, peripheral artery disease and transient ischaemic attack, with higher proportions among patients with HF with a history of stroke.

\section{Differences in depressive symptoms}

Table 2 shows the effect of the adjustment for multiple potential confounding variables on moderate and severe depression (CES-D). History of stroke was the only factor that remained in the model at both 12 and 18 months for risk of depression. This was most notable at 12 months with more than a twofold increased risk for both moderate (OR 2.29; 95\% CI 1.22 to $4.29, \mathrm{p}=0.010$ ) and severe (OR 2.83; $95 \%$ CI 1.27 to $6.28, \mathrm{p}=0.011$ ) depression. Type 2 diabetes was found to have an independent association with moderate depression at 18 months (OR 1.63; 95\% CI 1.02 to $2.61, \mathrm{p}=0.040$ ).

\section{Differences in quality of life}

History of stroke was the only factor that remained in the model at 12 and 18 months. The 12 month point was found to have the highest increased risk for disease-specific (OR 2.80; 95\% CI 1.61 to 4.84, $\mathrm{p}<0.001$ ) and generic (OR 2.00, 95\% CI 1.09 to $3.50, \mathrm{p}=0.019$ ) poor quality of life.

\section{Differences in HF management adherence and HF self-care behaviour}

History of stroke was the only factor to show an independent association with inadequate HF management adherence total scores at both 12 (OR $0.39,95 \%$ CI 0.18 to 0.81 , $\mathrm{p}=0.012)$ and 18 (OR $0.35,95 \% \mathrm{CI} 0.17$ to $0.72, \mathrm{p}=0.004)$ months (table 3 ). However, at 18 months comorbid transient ischaemic attack (OR $0.40,95 \%$ CI 0.19 to 0.78 ) and history of atrial fibrillation (OR 1.79, 95\% CI 1.04 to 3.07, $\mathrm{p}=0.035$ ) also significantly increased risk of inadequate HF management adherence. 
Table 1 Baseline characteristics as a function of HF and stroke comorbidity

\begin{tabular}{|c|c|c|c|c|}
\hline & $\begin{array}{l}\text { HF } \\
(n=918)\end{array}$ & $\begin{array}{l}\text { HF+stroke } \\
(n=105)\end{array}$ & $\begin{array}{l}\text { OR }(95 \% \mathrm{Cl}) \\
\text { unadjusted }\end{array}$ & $P$ value \\
\hline \multicolumn{5}{|l|}{ Demographics } \\
\hline Age mdn (IQR) & $73(57-89)$ & $75(63-87)$ & & 0.069 \\
\hline Male & $569(62 \%)$ & $70(67 \%)$ & $1.23(0.80$ to 1.88$)$ & 0.348 \\
\hline Married/living together & $542(60 \%)$ & $63(61 \%)$ & 0.97 (0.64 to 1.46$)$ & 0.872 \\
\hline \multicolumn{5}{|l|}{ Comorbidities } \\
\hline Type 1 diabetes mellitus & $94(10 \%)$ & $14(13 \%)$ & 1.35 (0.74 to 2.46$)$ & 0.330 \\
\hline Type 2 diabetes mellitus & $153(17 \%)$ & $33(31 \%)$ & 2.29 (1.47 to 3.58$)$ & $<0.001$ \\
\hline Transient ischaemic attack & $59(6 \%)$ & $24(23 \%)$ & 4.31 (2.55 to 7.30$)$ & $<0.001$ \\
\hline COPD & $238(26 \%)$ & $30(29 \%)$ & 1.14 (0.73 to 1.79$)$ & 0.559 \\
\hline History of atrial fibrillation & $392(43 \%)$ & $59(56 \%)$ & 1.72 (1.15 to 2.59$)$ & 0.008 \\
\hline Asthma & $36(4 \%)$ & $5(5 \%)$ & 1.23 (0.47 to 3.19$)$ & 0.678 \\
\hline Renal disease & $68(7 \%)$ & $10(10 \%)$ & 1.32 (0.66 to 2.64$)$ & 0.440 \\
\hline Liver disease & $23(3 \%)$ & $3(3 \%)$ & 1.15 (0.34 to 3.88$)$ & 0.828 \\
\hline Gastro-intestinal disease & $105(11 \%)$ & $16(15 \%)$ & 1.39 (0.79 to 2.46$)$ & 0.255 \\
\hline Hypertension & $385(42 \%)$ & $54(51 \%)$ & 1.47 (0.98 to 2.20$)$ & 0.064 \\
\hline Peripheral artery disease & 139 (15\%) & $29(28 \%)$ & 2.14 (1.34 to 3.40$)$ & 0.001 \\
\hline \multicolumn{5}{|l|}{ Cardiovascular risk factors } \\
\hline Body mass index & $27.1 \pm 5$ & $26.3 \pm 5$ & & 0.219 \\
\hline Systolic blood pressure & $118.2 \pm 21$ & $119.3 \pm 19$ & & 0.623 \\
\hline Diastolic blood pressure & $68.5 \pm 12$ & $67.5 \pm 11$ & & 0.448 \\
\hline \multicolumn{5}{|l|}{ Disease severity } \\
\hline LVEF & $33.7 \pm 14.3$ & $33.9 \pm 15.1$ & & 0.930 \\
\hline NYHA classification & & & & 0.650 \\
\hline II & $465(51 \%)$ & $48(47 \%)$ & & \\
\hline III & $410(45 \%)$ & $51(49 \%)$ & & \\
\hline IV & $30(3 \%)$ & $4(4 \%)$ & & \\
\hline Previous HF admission & $296(32 \%)$ & $38(36 \%)$ & 1.19 (0.78 to 1.82$)$ & 0.414 \\
\hline \multicolumn{5}{|l|}{ Medications } \\
\hline ACE inhibitors & $673(73 \%)$ & $71(68 \%)$ & 0.76 (0.49 to 1.17$)$ & 0.215 \\
\hline Angiotensin blockers & $110(12 \%)$ & $14(13 \%)$ & 1.13 (0.62 to 2.05$)$ & 0.688 \\
\hline Beta-blockers & $616(67 \%)$ & $61(58 \%)$ & $0.68(0.45$ to 1.03$)$ & 0.065 \\
\hline Diuretics & 878 (96\%) & $102(97 \%)$ & $1.55(0.47$ to 5.10$)$ & 0.468 \\
\hline Coumarin & $554(60 \%)$ & $71(68 \%)$ & 1.37 (0.89 to 2.11$)$ & 0.148 \\
\hline Antidepressants & 65 (7\%) & $6(6 \%)$ & 0.80 (0.34 to 1.88$)$ & 0.602 \\
\hline
\end{tabular}

Bold $p$ values represent significant alpha after Bonferroni correction $(p<0.002)$.

$\mathrm{ACE}$, angiotensin converting enzyme; COPD, chronic obstructive pulmonary disease; HF, heart failure; LVEF, left ventricular ejection; mdn, median; NYHA, New York Heart Association.

Table 3 shows the association between history of stroke and inadequate $\mathrm{HF}$ self-care at all time-points, with a 1.8-fold risk at 12 months (OR 1.80, 95\% CI 1.05 to 3.11, $\mathrm{p}=0.034)$ increasing to an almost threefold risk at 18 months (OR 2.87, 95\% CI 1.61 to 5.11, $\mathrm{p}<0.001$ ). Other significant predictors of inadequate HF self-care were age at baseline and 12 months, 1.02-fold increased risk on both occasions, and comorbid peripheral arterial disease at 18 months, 1.65 -fold increased risk.

Differences in clinical outcomes

Table 4 shows patients with HF with stroke fared worse across all rehospitalisations at 18 months compared with those without stroke; unadjusted HRs indicated greater 
Table 2 Predictors of moderate and severe depression in final model of multivariable logistic regression over 18 months

Predictors in final step of
model

Baseline

\begin{tabular}{|lll|}
\hline Gender & $1.60(1.22$ to 2.10$)$ & $\mathbf{0 . 0 0 1}$ \\
\hline Age & $0.99(0.97$ to 0.99$)$ & $\mathbf{0 . 0 3 7}$ \\
\hline $\begin{array}{l}\text { History of stroke } \\
12 \text { months }\end{array}$ & $1.57(1.03$ to 2.41$)$ & $\mathbf{0 . 0 3 6}$ \\
\hline $\begin{array}{l}\text { History of stroke } \\
\text { 18 months }\end{array}$ & $2.29(1.22$ to 4.29$)$ & $\mathbf{0 . 0 1 0}$ \\
\hline $\begin{array}{l}\text { History of stroke } \\
\text { Comorbid type II diabetes }\end{array}$ & $1.63(1.02$ to 2.61$)$ & $\mathbf{0 . 0 4 0}$ \\
\hline $\begin{array}{l}\text { Severe depression } \\
\text { (CES-D } \geq 24)\end{array}$ & & \\
\hline
\end{tabular}

Baseline

\begin{tabular}{|c|c|c|}
\hline Gender & 1.68 (1.22 to 2.32$)$ & 0.002 \\
\hline Age & 0.98 (0.97 to 0.99$)$ & 0.010 \\
\hline \multicolumn{3}{|l|}{12 months } \\
\hline History of stroke & 2.83 (1.27 to 6.28$)$ & 0.011 \\
\hline \multicolumn{3}{|l|}{18 months } \\
\hline Age & 0.98 (0.96 to 1.00$)$ & 0.076 \\
\hline History of stroke & 2.24 (1.03 to 4.88$)$ & 0.043 \\
\hline
\end{tabular}

Bold $p$ values represent significant alpha, $p<0.05$. Covariates entered in each model: age at index hospitalisation; gender; comorbid transient ischaemic attack; comorbid peripheral arterial disease; comorbid type 2 diabetes mellitus; history of atrial fibrillation; and history of stroke.

CES-D, Center for Epidemiologic Studies Depression Scale.

odds of all rehospitalisations at 18 months, ranging from 1.6 to 2.0. After adjusting for baseline age, sex, NYHA functional status and significant comorbidities patients with HF with stroke were up to 1.7 times more likely to be rehospitalised and 1.5 times more likely to experience all-cause mortality than patients with $\mathrm{HF}$ without stroke. The odds of all-cause mortality at 18 months and 3 years remained significantly higher in patients with HF with stroke compared with those without stroke (table 4). For example, at 3 years patients with HF with stroke had a $43 \%$ greater likelihood of dying from all-cause mortality, compared with those without stroke.

Figure 1 shows significant differences between patients with $\mathrm{HF}$ with and without stroke for cardiovascular, HF and all-cause rehospitalisations up to 18 months and all-cause mortality up to 3 years. Kaplan-Meier survival curves show patients with HF with stroke fared worse than those without stroke across all clinical outcomes. Compared with those without stroke, rehospitalisations at 18 months for patients with stroke were on average 84 days earlier
Table 3 Predictors of inadequate heart failure management adherence and self-care behaviour in final model of logistic multivariable regression over 18 months

\begin{tabular}{|c|c|c|}
\hline $\begin{array}{l}\text { Predictors in final step of } \\
\text { model }\end{array}$ & OR $(95 \% \mathrm{Cl})$ & $P$ value \\
\hline \multicolumn{3}{|l|}{$\begin{array}{l}\text { Inadequate HF } \\
\text { management adherence } \\
\text { (HFCQ;<3 of } 6 \text { behaviours }^{32} \text { ) }\end{array}$} \\
\hline \multicolumn{3}{|l|}{ Baseline } \\
\hline History of atrial fibrillation & $1.30(0.99$ to 1.71$)$ & 0.060 \\
\hline \multicolumn{3}{|l|}{12 months } \\
\hline History of stroke & $0.39(0.18$ to 0.81$)$ & 0.012 \\
\hline \multicolumn{3}{|l|}{18 months } \\
\hline History of stroke & $0.35(0.17$ to 0.72$)$ & 0.004 \\
\hline Comorbid TIA & $0.40(0.19$ to 0.78$)$ & 0.008 \\
\hline History of atrial fibrillation & 1.79 (1.04 to 3.07$)$ & 0.035 \\
\hline \multicolumn{3}{|c|}{ Inadequate self-care behaviour (EHFScB-9;<70²) } \\
\hline \multicolumn{3}{|l|}{ Baseline } \\
\hline Age & $1.02(1.01$ to 1.03$)$ & 0.001 \\
\hline History of stroke & 1.49 (0.97 to 2.29) & 0.069 \\
\hline \multicolumn{3}{|l|}{12 months } \\
\hline Age & $1.02(1.01$ to 1.03$)$ & 0.009 \\
\hline History of stroke & $1.80(1.05$ to 3.11$)$ & 0.034 \\
\hline \multicolumn{3}{|l|}{18 months } \\
\hline History of stroke & $2.87(1.61$ to 5.11$)$ & $<0.001$ \\
\hline $\begin{array}{l}\text { Comorbid peripheral } \\
\text { arterial disease }\end{array}$ & $1.65(1.05$ to 2.60$)$ & 0.030 \\
\hline
\end{tabular}

Bold $p$ values represent significant alpha, $p<0.05$. Covariates entered in each model: age at index hospitalisation; gender; comorbid transient ischaemic attack; comorbid peripheral arterial disease; comorbid type 2 diabetes mellitus; history of atrial fibrillation; and history of stroke.

EHFScB-9, European Heart Failure Self-care Behaviour scale; HF, heart failure; HFCQ, Heart Failure Compliance Questionnaire; TIA, transient ischaemic attack.

for cardiovascular rehospitalisations (mean 310 days, 95\% CI 265 to 355; mean 394 days, 95\% CI 380 to 408, Log Rank $16.48 \mathrm{p}<0.001), 61$ days earlier for HF rehospitalisations (mean 404 days, 95\% CI 363 to 444; mean 465 days, 95\% CI 453 to 477, Log Rank 17.39 p<0.001) and 78 days earlier for all-cause rehospitalisations (mean 261 days, 95\% CI 218 to 304; mean 339 days, 95\% CI 324 to 354 , Log Rank $13.31 \mathrm{p}<0.001)$. In regard to all-cause mortality, over the 3 years patients with HF with stroke died 167 days earlier (mean 702 days, 95\% CI 615 to 788) than patients with HF without stroke (mean 859 days, 95\% CI 833 to $884, \log \operatorname{Rank} 15.78 \mathrm{p}<0.001)$ and had a median survival time of 99 days less.

\section{DISCUSSION}

This secondary analysis of $\mathrm{COACH}$ data showed an association between HF and stroke and psychosocial, behavioural and clinical outcomes. The patients with HF 
Table 4 Rehospitalisation and mortality HRs as a function of HF and stroke comorbidity

\begin{tabular}{|c|c|c|c|c|c|c|}
\hline & \multicolumn{2}{|l|}{ n (\%) } & $\begin{array}{l}\text { HR } \\
\text { (95\% Cl) } \\
\text { (unadjusted) }\end{array}$ & $P$ value & $\begin{array}{l}\text { HR } \\
(95 \% \mathrm{Cl}) \text { adjusted: } \\
\text { age, sex, NYHA, } \\
\text { other comorbidities* }\end{array}$ & P value \\
\hline \multicolumn{7}{|l|}{ Clinical endpoints } \\
\hline \multicolumn{7}{|l|}{18 months post-discharge } \\
\hline CV rehospitalisation & $373(41 \%)$ & $60(57 \%)$ & 1.74 (1.32 to 2.29$)$ & $<0.001$ & 1.45 (1.09 to 1.94$)$ & 0.012 \\
\hline All-cause rehospitalisation & 495 (54\%) & $72(69 \%)$ & 1.57 (1.23 to 2.02$)$ & $<0.001$ & 1.31 (1.01 to 1.70$)$ & 0.044 \\
\hline HF rehospitalisation/death & $344(38 \%)$ & $67(64 \%)$ & 2.04 (1.57 to 2.66$)$ & $<0.001$ & 1.68 (1.27 to 2.22$)$ & $<0.001$ \\
\hline All-cause mortality & $230(25 \%)$ & $42(40 \%)$ & 1.78 (1.28 to 2.48$)$ & $<0.001$ & 1.46 (1.03 to 2.07$)$ & 0.033 \\
\hline \multicolumn{7}{|l|}{3 years post-discharge } \\
\hline
\end{tabular}

*Other comorbidities; type 2 diabetes mellitus, transient ischemia attack, peripheral artery disease, history of atrial fibrillation.

CV, cardiovascular; HF, heart failure; NYHA, New York Heart Association.

with a history of stroke had more comorbidities, poorer psychosocial and behavioural outcomes, earlier rehospitalisations and increased cardiovascular risk and mortality than patients with HF without stroke. Specifically, patients with HF with stroke had a twofold likelihood of being depressed, poorer HF management adherence and self-care and almost twice the likelihood of earlier rehospitalisations and all-cause mortality after adjusting for demographic variables and comorbidities. Differences between the two groups across outcomes tended to exacerbate over time, most notably from 12 months, indicating this as a critical point of patient decline that necessitates early intervention.

Comorbidities such as diabetes and peripheral artery disease greatly increase the physical and mental burden already imposed on patients with $\mathrm{HF}$ with and without stroke. ${ }^{17}$ Like other studies, we found a higher prevalence of type 2 diabetes, peripheral artery disease and transient ischaemic attack in patients with HF and stroke. ${ }^{35}$ Even so, it should be noted that in our population, patients were not severely impaired (NYHA functional status) with no differences between patients with HF with and without stroke. These findings are most likely the result of initial assessments for eligibility to participate in $\mathrm{COACH} .{ }^{21}$ In light of moderate disease severity and poor psychosocial, behavioural and clinical outcomes, the likelihood is that populations with more severe HF may experience even more severe outcomes.

Depression may occur in one in every three stroke patients. ${ }^{17}$ In HF populations this estimate is known to be far greater. ${ }^{14}$ Additionally, levels of depression are also known to increase alongside the number of comorbidities. ${ }^{11} 17$ In our study, there was almost a threefold likelihood of patients with HF with stroke having severe depressive symptoms at 12 months, which declined only to over a twofold likelihood at 18 months. With its associated poor treatment adherence, lack of energy and motivation and social withdrawal, ${ }^{11-13}$ sustained levels of depressive symptoms among patients with HF with stroke draw attention to the vulnerability of this population and the need for screening, referral and engagement in management strategies. Our finding that comorbid type 2 diabetes was a stronger predictor of more severe depression than other factors (history of atrial fibrillation, hypertension and peripheral artery disease) among patients with HF with stroke compared with those without is intriguing and warrants further study, though an additional comorbidity such as diabetes is likely to increase the burden on patients and may exacerbate depression, which is known to be high in patients with diabetes alone. $^{36}$

People with conditions such as HF and stroke are commonly found to report poor quality of life and wellbeing. ${ }^{37}$ Together, HF and stroke would likely augment any such impact, as found in our study. Similar to our findings on depression, patients with $\mathrm{HF}$ and stroke fared worse across both measures of quality of life at 12 and 18 months, a finding aligned with previous studies, indicating the degree of the decrement in quality of life is often proportional to the severity of depressive symptoms. ${ }^{37}$ The enduring continuation of increased rehospitalisations may explain poor physical quality of life at 18 months for this patient population. ${ }^{6-9}$ In light of the poor prognosis of patients with HF and stroke, where symptoms can at best be controlled rather than cured, efforts to maintain and improve quality of life should be considered a primary goal in their disease management.

Achieving optimal self-care by patients with HF is widely regarded as essential goal of disease management. ${ }^{1} 3338$ However, HF self-care behaviour is complicated by factors such as ageing, comorbidities, cognitive impairment, frailty and limited social support. ${ }^{38}$ Our findings highlight the difficulty of maintaining adequate HF self-care and management adherence. Together with stroke, a history of atrial fibrillation, comorbid transient ischaemic attack and peripheral artery disease contributed to deficiencies in these aspects of care. This is likely due to the 
A. CV rehospitalisation by $\mathbf{1 8}$ months

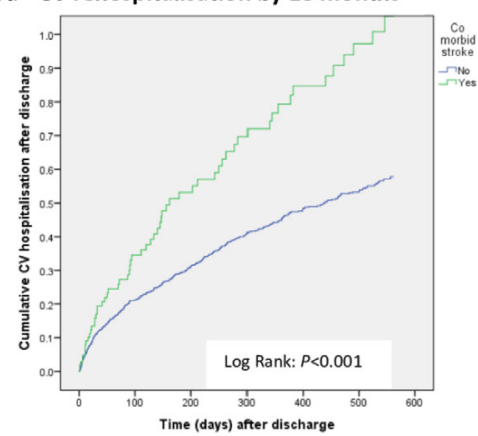

Number at risk

\begin{tabular}{lcccc}
\hline Without Stroke & 918 & 632 & 553 & 102 \\
With Stroke & 105 & 53 & 38 & 6
\end{tabular}

C. HF rehospitalisation by $\mathbf{1 8}$ months

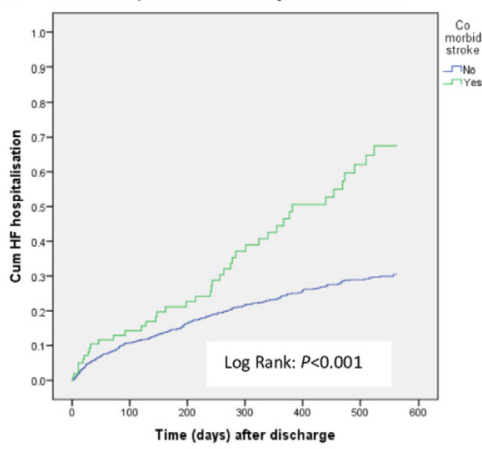

B. All-cause rehospitalisation bv 18 months

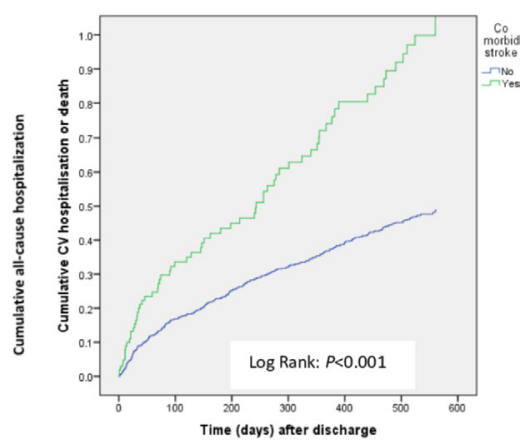

Figure 1 Kaplan-Meier event curves for patients with HF with $(n=105)$ and without $(n=918)$ stroke across (A) CV rehospitalisation by 18 months, (B) HF rehospitalisation by 18 months, (C) CV rehospitalisation or death by 18 months, and (D) all-cause mortality by 3 years as a function of HF and stroke comorbidity. Kaplan-Meier curves represent a comparison of patients with HF with (green) and without (blue) stroke, for days to rehospitalisation (A; B; C) or to death (D). Kaplan-Meier curves identified patients with HF with stroke as significantly $(p<0.001)$ worse than patients with HF without stroke across all clinical outcomes. 'Number at risk' columns are in 200 day increments for rehospitalisation's, and 400 day increments for mortality. CV, cardiovascular; HF, heart failure.

additive impact of major chronic disabling conditions contributing to a more burdensome and complex HF management and self-care regimen. This issue needs to be considered carefully when planning with patients and carers how best to optimise disease management strategies. Patients with HF and stroke had poorer engagement in HF self-care and management adherence from 12 months, compared with those without stroke, with differences between the two groups in HF self-care being clinically significant according to interpretability of the EHFScBS-9. ${ }^{31}$ This may be explained by HF and stroke being established burdensome conditions, ${ }^{37}$ both requiring intensive and enduring support. Also, patients with HF and stroke, compared with those without stroke, had significantly more comorbidities, a known barrier to successful self-care. ${ }^{38}$ Thus, interventions which focus on prioritising specific aspects of self-care for $\mathrm{HF}$ and stroke independently may be more effective than general support for patients dealing with such burdensome and complex comorbidities.

In regard to clinical outcomes, our findings of approximately twice the increased risk of hospitalisation and mortality in patients with HF with stroke concur with those of other studies, ${ }^{5-8}$ such as one showing patients with stroke after HF had a 2.3 times higher risk of dying than patients without stroke ${ }^{5}$ and another showing the odds of dying within 30 days and 1 year since stroke diagnosis, was close to two times greater for patients who had 
pre-existing HF. ${ }^{6}$ Additionally, in our study, comorbid HF and stroke was identified as a predictor of rehospitalisations at 18 months and all-cause mortality up to 3 years independent of age, gender, HF functional status and presence of other comorbidities such as peripheral artery disease, transient ischaemic attack and type 2 diabetes. Also, patients with HF and stroke were rehospitalised up to 84 days earlier and died an average of 5 months earlier compared with those without stroke.

Our findings highlight poor psychosocial, behavioural and clinical outcomes for patients with $\mathrm{HF}$ and stroke which, taken together, indicate a diminished likelihood of early and successful recovery. An assessment of the particular needs of this significant and growing patient group should inform the design of appropriately-tailored care management strategies, which can then be evaluated for effectiveness. Patient choice and preferences should be central to such efforts.

\section{Limitations}

This was a secondary analysis of COACH data and therefore was constrained by the methods employed in the original study. ${ }^{2122}$ Applicable to all observational trials, correlation does not prove causation. Although we found no statistically significant differences between proportions of patients with HF with and without stroke across intervention and control groups, our study was limited by the lack of patients with severe HF, which may have caused a bias in terms of minimising the magnitude of the effects on outcome. Also, the absence of a measure of stroke severity, a known predictor of functional dependency, ${ }^{35}$ may have impeded our interpretation of clinical outcomes. Another limitation is the absence of recurrent stroke or mortality due to stroke as a clinical outcome measure. It would be valuable information to know if patients with $\mathrm{HF}$ and stroke were more likely to have recurrent stroke, as this could potentially influence depression, quality of life, adherence to HF care and clinical outcomes. Using the medical record to determine the presence or absence of prior stroke does not capture severity and may be inaccurate due to poor history taking or documentation and this may have influenced the findings. This is an important consideration when patients with 'history of stroke' in their medical record were more likely to have severe stroke. Lastly, although clinical interview, the gold standard, was not used to diagnose depression, presence of depressive symptoms was assessed via the CES-D which has been well-validated, in both HF and stroke populations, ${ }^{24}$ to identify patients who are at high risk of developing a depressive disorder.

\section{CONCLUSIONS}

To our knowledge, this is the first study to examine psychosocial, behavioural and clinical outcomes in patients with HF with stroke compared with those without stroke. These findings not only confirm the poor prognosis in patients with HF with stroke, but also that depression is more common, quality of life, HF self-care and HF management adherence are poorer and risk of rehospitalisation and mortality are greater in these patients. Further, 12 months post-discharge was identified as a point of heightened vulnerability for those experiencing this comorbidity that may be ameliorated by strategies that address cardiovascular risk and psychosocial and behavioural factors. This study highlights the clinical relevance of the complex interplay between $\mathrm{HF}$ and stroke that requires further investigation and warrants the need for long-term, integrated disease management pathways for patients with comorbid HF and stroke which span the hospital-home interface.

\section{Author affiliations \\ ${ }^{1}$ School of Nursing and Midwifery, Queen's University Belfast, Belfast, UK ${ }^{2}$ Department of Cardiology, University of Groningen, University Medical Center Groningen, Groningen, The Netherlands \\ ${ }^{3}$ Department of Social and Welfare Studies, Linköping University, Linköping, Sweden ${ }^{4}$ Faculty of Health, Deakin University, Burwood, Victoria, Australia \\ ${ }^{5}$ Department of Epidemiology, University of Groningen, University Medical Center Groningen, Groningen, The Netherlands \\ ${ }^{6}$ Nursing Research Institute, Australian Catholic University, Sydney, New South Wales, Australia \\ ${ }^{7}$ School of Clinical Sciences, Monash University, Clayton, Victoria, Australia}

Contributors CFS, TJ, DRT and MLG conceived and designed the study and drafted the manuscript. MLG, CFS, TJ and DJV analysed and guided interpretation of data. MHLW, IL-L, SM, JC critically advised on important intellectual content and contributed to drafting of the manuscript. All authors read and approved the manuscript. All authors approved the final version to be published. CFS and TJ are responsible for overall content as guarantors accountable to all aspects of the work.

Funding The $\mathrm{COACH}$ study was supported by a program grant from the Netherlands Heart Foundation (grant 2000Z003); DJV is a Clinical Established Investigator of the Netherlands Heart Foundation (grant D97.017).

Competing interests None declared.

Patient consent for publication Not required.

Provenance and peer review Not commissioned; externally peer reviewed.

Data sharing statement The data that supports the findings of this study are available, on reasonable request, from the corresponding author.

Open access This is an open access article distributed in accordance with the Creative Commons Attribution Non Commercial (CC BY-NC 4.0) license, which permits others to distribute, remix, adapt, build upon this work non-commercially, and license their derivative works on different terms, provided the original work is properly cited, appropriate credit is given, any changes made indicated, and the use is non-commercial. See: http://creativecommons.org/licenses/by-nc/4.0/.

\section{REFERENCES}

1. Ponikowski P, Voors AA, Anker SD, et al. 2016 ESC Guidelines for the diagnosis and treatment of acute and chronic heart failure: The Task Force for the diagnosis and treatment of acute and chronic heart failure of the European Society of Cardiology (ESC)Developed with the special contribution of the Heart Failure Association (HFA) of the ESC. Eur Heart J 2016;37:2129-200.

2. GBD 2013 Mortality and Causes of Death Collaborators. Global, regional, and national age-sex specific all-cause and causespecific mortality for 240 causes of death, 1990-2013: a systematic analysis for the Global Burden of Disease Study 2013. Lancet 2015;385:117-71.

3. Cuadrado-Godia E, Ois A, Roquer J. Heart failure in acute ischemic stroke. Curr Cardiol Rev 2010;6:202-13.

4. Hamatani $Y$, Iguchi M, Nakamura M, et al. Incidence and predictors of ischemic stroke during hospitalization for congestive heart failure. Heart Vessels 2016;31:1154-61. 
5. Witt BJ, Brown RD, Jacobsen SJ, et al. Ischemic stroke after heart failure: a community-based study. Am Heart J 2006;152:102-9.

6. Pongmoragot J, Lee DS, Park TH, et al. Stroke and heart failure: clinical features, access to care, and outcomes. J Stroke Cerebrovasc Dis 2016;25:1048-56.

7. Adelborg K, Szépligeti S, Sundbøll J, et al. Risk of stroke in patients with heart failure: a population-based 30-year cohort study. Stroke 2017;48:1161-8.

8. Katsanos AH, Parissis J, Frogoudaki A, et al. Heart failure and the risk of ischemic stroke recurrence: A systematic review and metaanalysis. J Neurol Sci 2016;362:182-7.

9. Christiansen MN, Køber L, Weeke P, et al. Age-specific trends in incidence, mortality, and comorbidities of heart failure in Denmark, 1995 to 2012. Circulation 2017;135:1214-23.

10. Gurbel PA, Tantry US. Antiplatelet and anticoagulant agents in heart failure. JACC Heart Fail 2014;2:1-14.

11. Pan A, Sun Q, Okereke OI, et al. Depression and risk of stroke morbidity and mortality: a meta-analysis and systematic review. JAMA 2011;306:1241-9.

12. Hackett ML, Pickles K. Part I: frequency of depression after stroke: an updated systematic review and meta-analysis of observational studies. Int J Stroke 2014;9:1017-25.

13. Adelborg K, Schmidt M, Sundbøll J, et al. Mortality risk among heart failure patients with depression: a nationwide population-based cohort study. J Am Heart Assoc 2016;5:e004137.

14. Rutledge T, Reis VA, Linke SE, et al. Depression in heart failure. J Am Coll Cardiol 2006;48:1527-37.

15. Samartzis L, Dimopoulos S, Tziongourou M, et al. Effect of psychosocial interventions on quality of life in patients with chronic heart failure: a meta-analysis of randomized controlled trials. J Card Fail 2013;19:125-34.

16. Klainin-Yobas P, Ng SH, Stephen PDM, et al. Efficacy of psychosocial interventions on psychological outcomes among people with cardiovascular diseases: a systematic review and meta-analysis. Patient Educ Couns 2016;99:512-21.

17. Benjamin EJ, Blaha MJ, Chiuve SE, et al. Heart disease and stroke statistics-2017 update: a report from the American Heart Association. Circulation 2017;135:e146-e603.

18. Fang $N$, Jiang $M$, Fan $Y$. Ideal cardiovascular health metrics and risk of cardiovascular disease or mortality: A meta-analysis. Int $J$ Cardiol 2016;214:279-83.

19. Yang Q, Cogswell ME, Flanders WD, et al. Trends in cardiovascular health metrics and associations with all-cause and CVD mortality among US adults. JAMA 2012;307:1273-83.

20. Folsom AR, Shah AM, Lutsey PL, et al. American Heart Association's Life's Simple 7: avoiding heart failure and preserving cardiac structure and function. Am J Med 2015;128:970-6.

21. Jaarsma T, Van Der Wal MH, Hogenhuis J, et al. Design and methodology of the COACH study: a multicenter randomised Coordinating study evaluating Outcomes of Advising and Counselling in Heart failure. Eur J Heart Fail 2004;6:227-33.

22. Jaarsma T, van der Wal MH, Lesman-Leegte I, et al. Effect of moderate or intensive disease management program on outcome in patients with heart failure: Coordinating Study Evaluating Outcomes of Advising and Counseling in Heart Failure (COACH). Arch Intern Med 2008;168:316-24.
23. Radloff LS. The CES-D scale: a self-report depression scale for research in the general population. Appl Psychol Meas 1977;1:385-401.

24. Moon JR, Huh J, Song J, et al. The center for epidemiologic studies depression scale is an adequate screening instrument for depression and anxiety disorder in adults with congential heart disease. Health Qual Life Out 2017;15:176.

25. Rector TS, Cohn JN. Assessment of patient outcome with the Minnesota Living with Heart Failure questionnaire: reliability and validity during a randomized, double-blind, placebo-controlled trial of pimobendan. Pimobendan Multicenter Research Group. Am Heart J 1992;124:1017-25.

26. Behlouli $H$, Feldman DE, Ducharme A, et al. Identifying relative cutoff scores with neural networks for interpretation of the Minnesota Living with Heart Failure questionnaire. Conf Proc IEEE Eng Med Biol Soc 2009;2009:6242-6.

27. Cantril H. The pattern of human concerns. New Brunswick, NJ: Rutgers University Press, 1965.

28. Organisation for Economic Cooperation and Development. Guidelines on measuring subjective well-being. Paris: OECD, 2013.

29. Jaarsma T, Arestedt KF, Mårtensson J, et al. The European Heart Failure Self-care Behaviour scale revised into a nine-item scale (EHFScB-9): a reliable and valid international instrument. Eur $J$ Heart Fail 2009;11:99-105.

30. Vellone E, Jaarsma T, Strömberg A, et al. The European heart failure self-care behaviour scale: new insights into factorial structure, reliability, precision and scoring procedure. Patient Educ Couns 2014;94:97-102.

31. Wagenaar KP, Broekhuizen BD, Rutten FH, et al. Interpretability of the european heart failure self-care behaviour scale. Patient Prefer Adherence 2017;11:1841-9.

32. Jaarsma T, Strömberg A, Ben Gal T, et al. Comparison of self-care behaviors of heart failure patients in 15 countries worldwide. Patient Educ Couns 2013;92:114-20.

33. Evangelista LS, Berg J, Dracup K. Relationship between psychosocial variables and compliance in patients with heart failure. Heart Lung 2001;30:294-301.

34. Nieuwenhuis MM, Jaarsma T, van Veldhuisen DJ, et al. Factors associated with patient delay in seeking care after worsening symptoms in heart failure patients. J Card Fail 2011;17:657-63.

35. Vemmos K, Ntaios G, Savvari P, et al. Stroke aetiology and predictors of outcome in patients with heart failure and acute stroke: a 10-year follow-up study. Eur J Heart Fail 2012;14:211-8.

36. Snoek FJ, Bremmer MA, Hermanns N. Constructs of depression and distress in diabetes: time for an appraisal. Lancet Diabetes Endocrinol 2015;3:450-60.

37. Wikman A, Wardle J, Steptoe A. Quality of life and affective well-being in middle-aged and older people with chronic medical illnesses: a cross-sectional population based study. PLoS One 2011;6:e18952

38. Jaarsma T, Cameron J, Riegel B, et al. Factors related to self-care in heart failure patients according to the middle-range theory of self-care of chronic illness: a literature update. Curr Heart Fail Rep 2017;14:71-7. 